\title{
ELIMINATION OF FIBERS CREATED FROM THE ELECTRODE ROD AND INFLUENCE ON ELECTROSPINNING
}

\author{
Ondřej BAŤKA, Josef SKŘIVÁNEK
}

TUL - Technical University of Liberec, Department of Textile Machine Design, Liberec, Czech Republic, EU, ondrej.batka@tul.cz

https://doi.org/10.37904/nanocon.2020.3729

\begin{abstract}
The article deals with the production of nanofibers using the AC-electrospinning method. It focuses on research into the possibility of eliminating the formation of fibers, which are not desirable. Ways to prevent the formation of these fibers have been proposed and tested experimentally. The influence on the electrospinning process and also on the size of production productivity was proved. Simultaneously, simulations were performed, which showed the electric field's dependence on the electrode's active part at its height. The dependence of the productivity of electrospinning on the height of the spinning electrode experimentally was found.
\end{abstract}

Keywords: Electric field, spinning electrode, electrospinning

\section{INTRODUCTION}

This research aimed to eliminate fiber drift from the spinning electrode's rod during AC-electrospinning [1]. These electrodes consist of parts for the transport and outflow of the polymer solution and an active part from which the spinning occurs [2]. They are usually used for the production of linear nanofiber structures [3]. The electrode diagram is shown in Figure 1 a). Since the polymer solution flows down the electrode rod's surface, long bundles of fibers sometimes form from this part. However, these bundles are not caught by the siding of fibers formed on the conical part of the electrode and fall off onto the lid of the container with the polymer solution and the machine table. Thus, there is contamination and excessive consumption of material that is not used in the final product. A single-stage electrode with a diameter value of 22 millimeters (Figure $\mathbf{1}$ b)) was used for the tests.

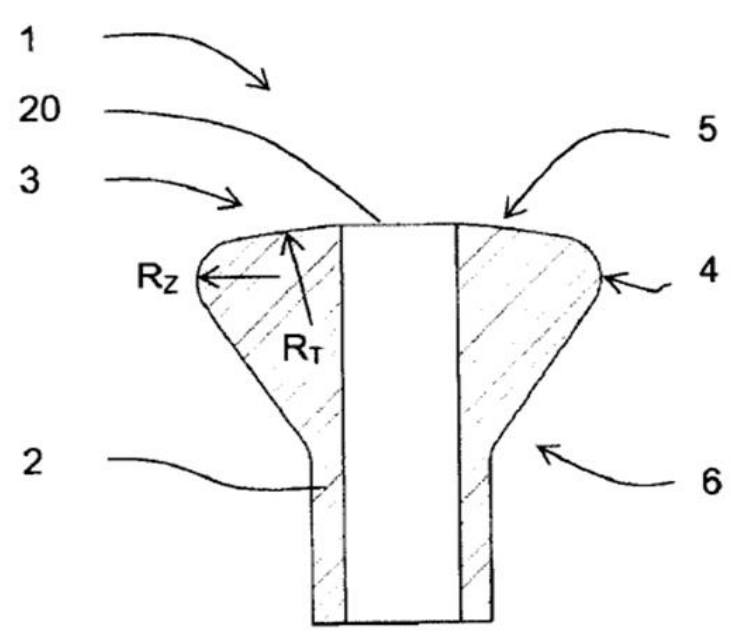

a)

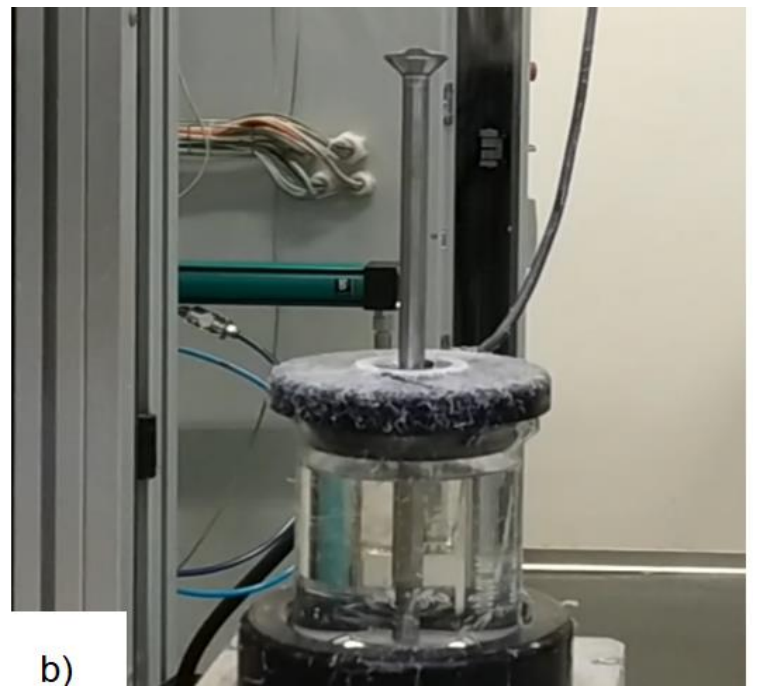

b)

Figure 1 a) scheme of spinning electrode: (2) electrode rod, (5) (6) polymeric solution transporting surfaces, (4) active spinning surface [1]; b) picture of real spinning electrode used for experiments 


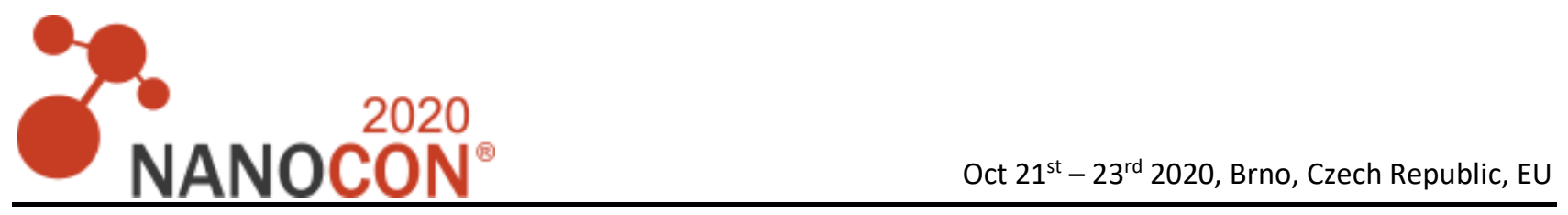

\section{SOLVING POSSIBILITIES}

Some options to prevent flights have been tested. One of them is shown in Figure 2 a). A metal tube was inserted around the stem of the electrode, which should prevent flying. However, as can be seen from the figure, some of the fibers formed on the cone are caught by the top of the tube and gradually deposited on it until the whole process of nanofiber production practically stops. Figure $\mathbf{2}$ b) shows a variant where the pipe has been shortened. As can be seen from the figure, the fibers are also deposited on and on the shorter tube. Although this is done in a visibly smaller amount, it can be assumed that after a more extended period of time, the increase will also be considered. The pipe, therefore, does not provide any solution to avoid pollution and excessive consumption of material.

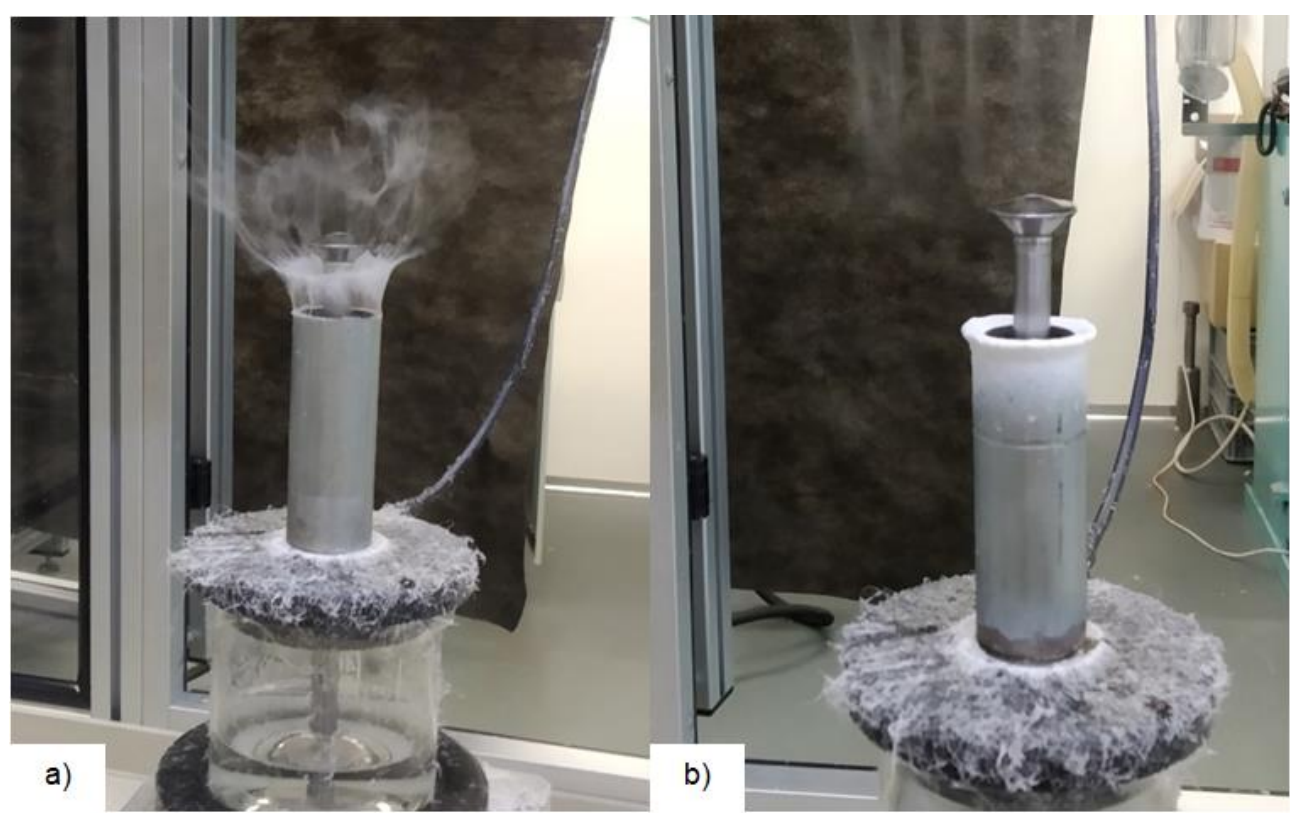

Figure 2 electrode with the covering tube a) longer variant, b) shorter variant

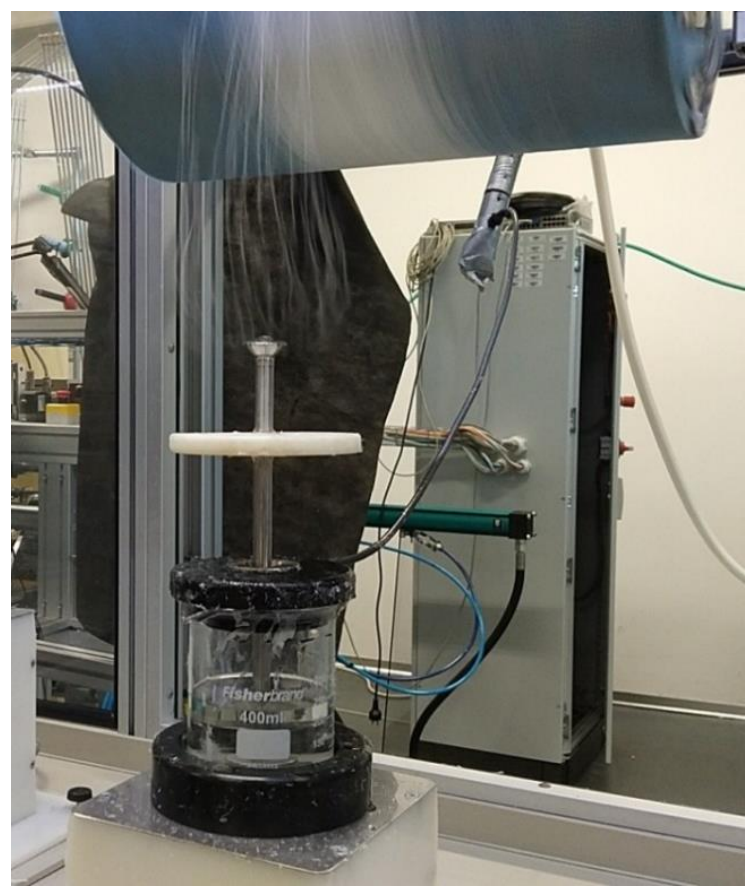

Figure 3 electrode with disc 
Another tried and tested way to prevent fiber escapes was to use a shielding disk, which should electrically shield the electrode rod and ensure that the rod's electric field is low enough to prevent spinning. Figure 3 shows this.

The upper surface of the disk was $40 \mathrm{~mm}$ from the top of the electrode. The tests with the shielding disk observed that long bundles of fibers do not fall off. However, after a longer spinning time, a small amount of dirt was observed on the disc. However, this is a phenomenon that cannot be completely suppressed. These are probably fine fibers formed on the electrode's active surface and are not captured by the stream of nanofibers. The shield disk essentially simulates the polymer container's lid, suggesting that the electrode rod could be shorter.

\section{MEASUREMENT OF SPINNING PRODUCTIVITY}

Experiments with electrode rod shielding have been supplemented with productivity measurements to determine how tube or disk shielding affects nanofiber production productivity. The voltage signal applied to the electrode had the shape of a sine function with a frequency of $50 \mathrm{~Hz}$. For each electrode treatment variant, experiments were performed for voltage values with voltage values of $28.5 \mathrm{kV}, 32 \mathrm{kV}$ and $35.4 \mathrm{kV}$. A $10 \%$ solution of Movital H60B PVB in ethanol was used for the experiments. The results of the experiments are shown in the graph in Figure 4. The productivity dependences on voltage for the three electrode variants are shown - the base electrode, the electrode with the covering tube and the electrodes with the disk $40 \mathrm{~mm}$ away from the top of the electrode. It can be seen from the graph that both selected solutions to eliminate unwanted fiber drop have an impact on productivity. In both cases, it was reduced by approximately ten percent. Furthermore, productivity measurements were performed for different disk positions and electrode heights at two voltage values on the electrode. Figure 5 shows the dependences of production productivity on electrode height. It should be noted that at the electrode's height of 30 millimeters, the electrospinning process was already so unstable, and the nanofibers produced were so small that it was not possible to deposit them on a collection drum and perform weighing. At the height of 20 millimeters, the electrospinning process no longer occurs. The fibers were not produced. For this reason, the graph for this distance shows a zero productivity value. The graph shows that with the height of the electrode, productivity increases up to a specific value when no further increase has an effect.

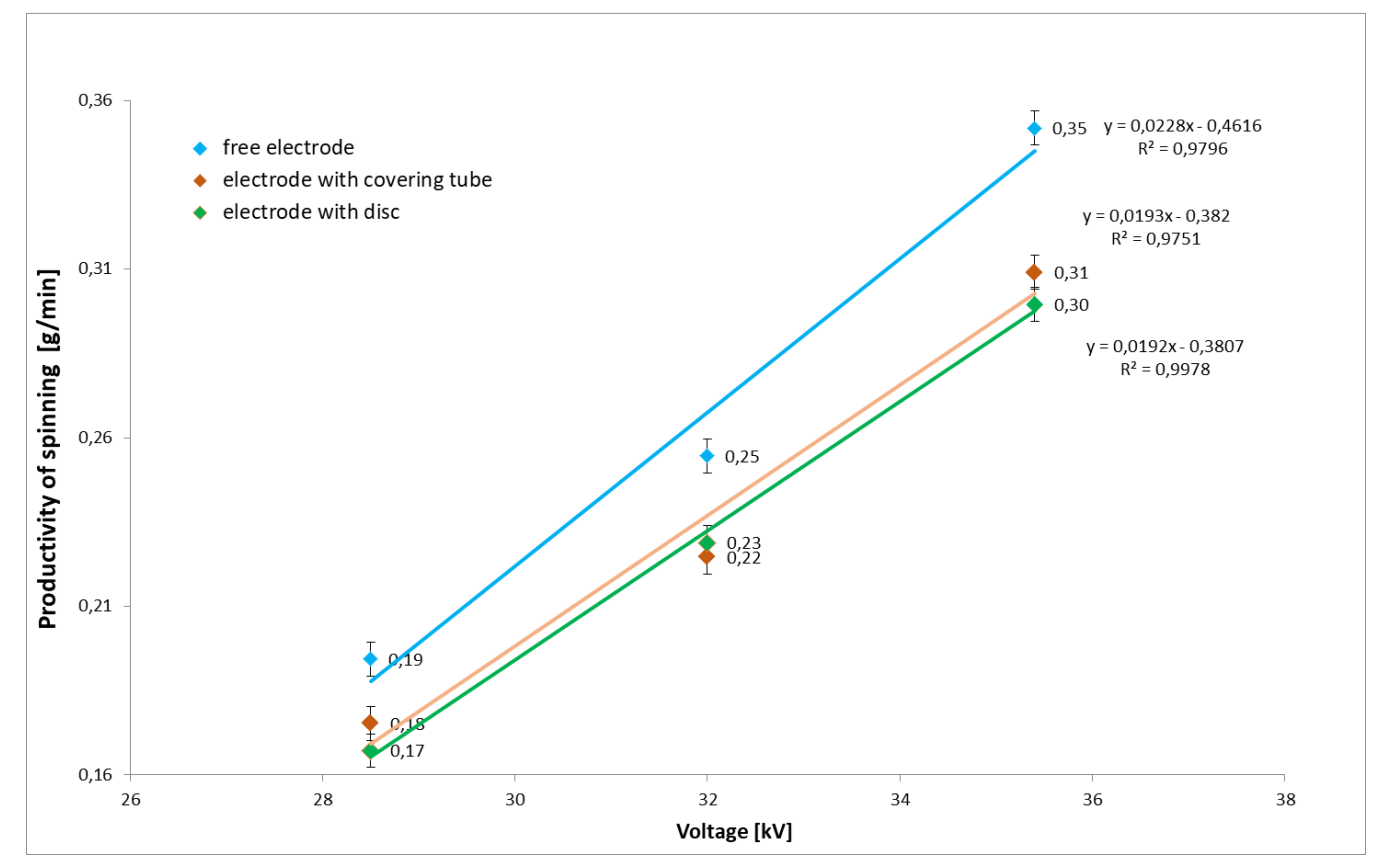

Figure 4 Dependence of productivity on voltage for different variants of the electrode covering 

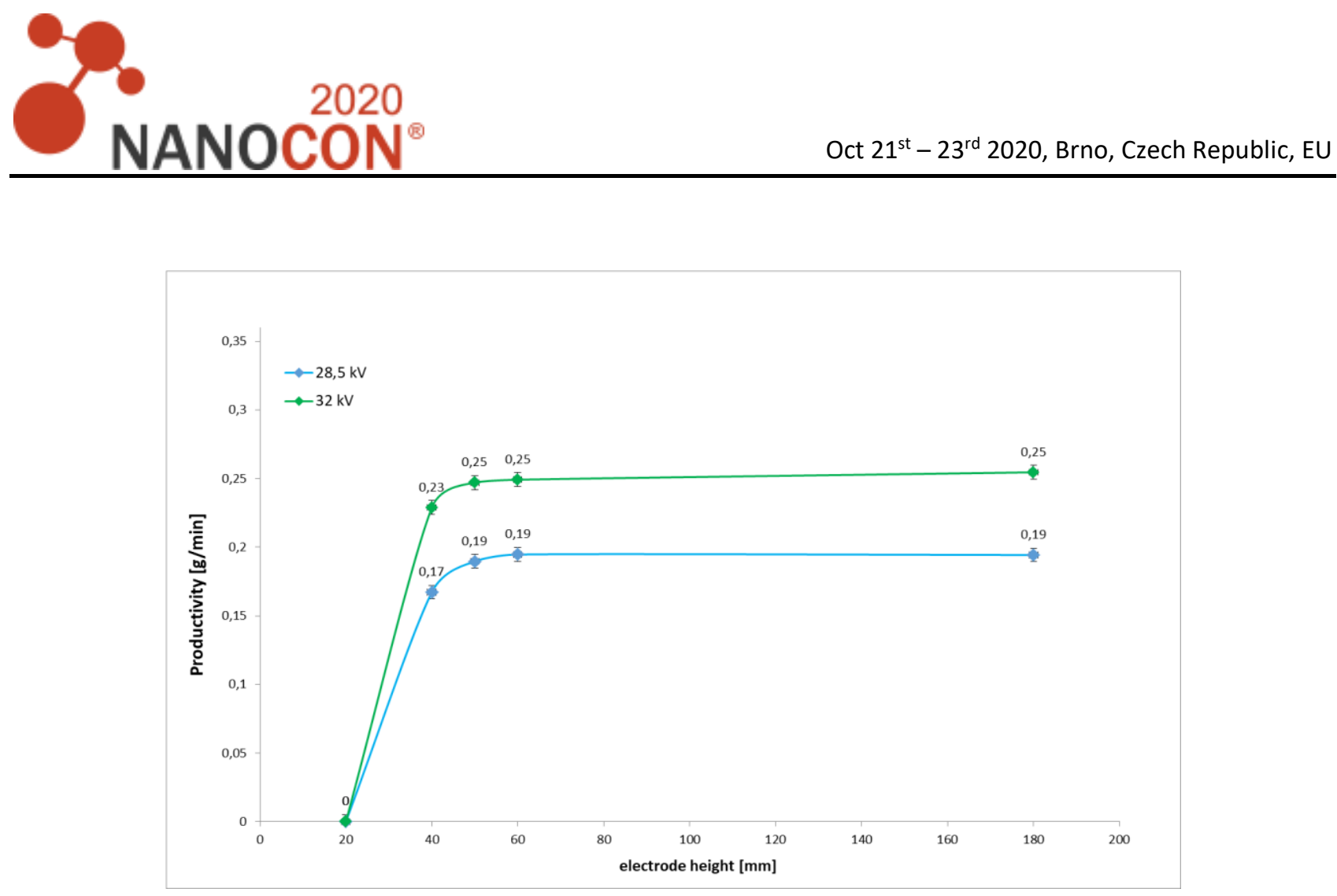

Figure 5 Dependence of productivity on electrode height

\section{SIMULATIONS}

The research was supplemented by simulations of the electric field distribution around the spinning electrode. Simulations were performed for different electrode heights to determine the dependence of the electric field's value in the active part of the electrode on its height. Autodesk Simulation Mechanical software was used for the simulations. They were performed for electrode voltages of $30 \mathrm{kV}$ and $0 \mathrm{~V}$ at the boundary of the distant surroundings. Figure 6 shows the dependence of the electric field active surface of the electrode on electrode height. It is evident from the dependence that the electric field's value on the electrode's active surface increases with the electrode's increasing height. It can be assumed that the cover of the electrode, located on the bottom, or the shielding disk influences the electric field's distribution. This dependence is probably also related to the effect on productivity, which was described in the previous chapter.

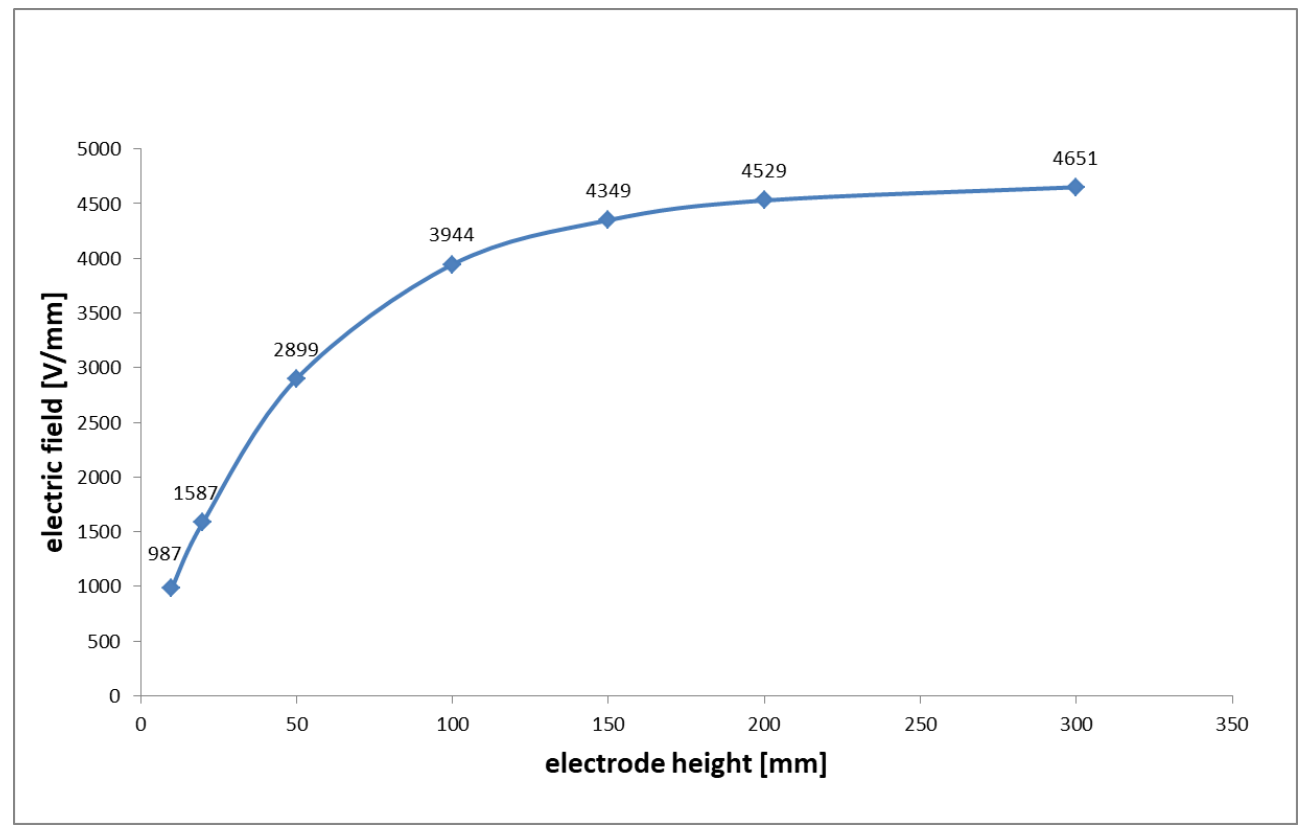

Figure 6 Dependence of the electric field of the active electrode surface on the height of the electrode 


\section{CONCLUSION}

Experiments show that it is possible to find ways to eliminate unwanted emissions of nanofibers from the rod of the spinning electrode. The use of a tube threaded around the electrode rod proved inappropriate, as nanofibers were trapped at the edge of the tube. The use of a disk or the possibility of shortening the spinning electrode rod has proven to be effective. However, it has been shown that as the height of the electrode decreases, the productivity of nanofiber production decreases. Corresponding to this is also the result of simulations, which showed that the electric field's value on the electrode's active surface decreases with the shortening of the electrode rod.

\section{ACKNOWLEDGEMENTS}

This publication was written at the Technical University of Liberec as part of the project with the support of the Specific University Research Grant, as provided by the Ministry of Education, Youth and Sports of the Czech Republic in the year 2020.

\section{REFERENCES}

[1] KOCIS, L,. POKORNY, P., LUKÁŠ, D., MIKEŠ, P., CHVOJKA, J., KOŠŤÁKOVÁ, E., MíČKOVÁ, A., Method for production of polymeric nanofibres by spinning of solution or melt of polymer in electric field, and a linear formation from polymeric nanofibers prepared by this method. EP 2931951

[2] BERAN, J., VALTERA, J., BÍLEK, M., SKŘIVÁNEK, J., KOŠŤÁKOVÁ, E., Method for producing polymeric nanofibres by electrospinnig a polymer solution or melt, a spinning elektrode for performing the metod and a device for producing polymeric nanofibers equipment with at least one cush spinning electrode. EP 3394328

[3] VALTERA, J., KALOUS, T., POKORNY, P., BATKA, O., BILEK, M., CHVOJKA, J., LUKAS, D. Fabrication of dualfunctional composite yarns with a nanofibrous envelope using high throughput $A C$ needleless and collectorless electrospinning. Scientific Reports. [online]. 2019, vol. 9, no. 1. Available from: https://doi.org/doi:10.1038/s41598019-38557-z.

[4] KOMAREK, J., VALTERA, J., SOUKUPOVA, J., VYSLOUZILOVA, L., SKRIVANEK, J., ZABKA, P., BERAN, J., LUKAS, D. Verification of the mathematical model of the rod electrode in the electrospinning process. In: Nanocon 2015, $7^{\text {th }}$ International Conference on Nanomaterials. Ostrava: TANGER, 2015.

[5] RŮŽıČKOVÁ, J. Electrostatic spinning of nano fibres. Liberec: Technical University of Liberec, 2006, p 11. ISBN 80-7372-066-3.

[6] POKORNY, P. Effective AC needleless and colector less electrospinning for yarn production. Physical Chemistry Chemical Physics. 2014, vol. 16, pp. 816-822.

[7] PEJCHAR, K., VYSLOUŽILOVÁ, L., POKORNÝ, P., BÍLEK, M., BERAN, J., LUKÁŠ, D. The slit needleless electrode for the electrospinning. In: NANOCON 2013 - 5th International Conference. Tanger, 2013, pp. 172-177. 